\title{
Study on Knowledge of Intravenous Injection, Self-confidence, Competence and Critical Thinking Disposition in Nursing Student
}

\author{
Ae-Ri-Na Nam ${ }^{1}$, Do-Young Lee ${ }^{2}$ and Gye-Hyun Jung ${ }^{3 *}$ \\ ${ }^{1}$ Ajou University Hospital, Korea \\ ${ }^{2}$ Department of Nursing, Changshin University, Korea \\ ${ }^{3}$ Department of Nursing, Jeonbuk Science College, Korea \\ ${ }^{1}$ aerina81@gmail.com, ${ }^{2}$ shine@cs.ac.kr, ${ }^{3}$ ghjung@jbsc.ac.kr
}

\begin{abstract}
This study was to explore the convergence relationship between intravenous catheter knowledge, self-confidence, competence, and critical thinking disposition in nursing students. The study follows a descriptive, cross-sectional design and the participants were 158 nursing students. Data were collected using self-report questionnaires and practice evaluation. There was a significantly positive correlation between self-confidence and competence. Also, critical thinking disposition is correlated with self-confidence. Conclusion: To improve nurse students' nursing practice of intravenous catheters, it is necessary to develop an education program for improving their self-confidence, competence, and critical thinking disposition.
\end{abstract}

Keywords: Nursing student, Intravenous catheter, Knowledge, Self-confidence, Competence, Critical thinking disposition

\section{Introduction}

Intravenous injection is the best measure that can expect exact and quick effects during an emergency, acute care, and transfusion [1]. Since it is implemented for more than $80 \%$ of inpatient [2] and invasive procedures, it is one of the greatest fears for the patient. Also, as diverse complications are caused for the patient such as phlebitis, infiltration, infection related to catheter insertion, etc. if the intravenous injection is not performed correctly, it is important to educate the correct intravenous injection method the nursing student [3]

Recently, the medical dispute related to intravenous injection is being increased and the legal responsibility of the nurse is increased in intravenous injection management. So, in the curriculum of nursing students, to enhance the safety and well-being of the patient, it is necessary to find out the measures to enhance intravenous injection competence.

The curriculum of the nursing department on intravenous injection provides to practice the intravenous injection through the basic nursing practice in the school and to observe or perform the intravenous injection personally through the clinical practice education of junior and senior years [4] However, since the clinical practice education is inclined to simple nursing activity as the patient's rights and safety are emphasized, more than $70 \%$ of the nursing students just observe the intravenous injection [5]. Then, nursing students are

Article history:

Received (July 28, 2019), Review Result (August 30, 2019), Accepted (October 6, 2019) 
experiencing the limitation in applying what they have learned to the clinical site [6], which may result in the degradation of self-confidence in intravenous injection performance. Since the nursing student's self-confidence related to the practice may have diverse influences on the practice satisfaction, interest, competence, etc [7], the change in the curriculum is required to enhance the self-confidence related to intravenous injection in the nursing student.

In the meantime, the critical thinking disposition refers to the motive and attitude to try to think critically placing importance on the critical thinking disposition [8]. The higher the critical thinking disposition of nursing students, the more their nursing competence can be enhanced [5]. However, in the research related to the intravenous injection of nursing students, there is a lot of research knowledge on intravenous injection, self-confidence, and competence but there is no research on these variables and the critical thinking disposition.

Therefore, this study was intended to provide the basic data to establish the strategy for the efficient application of the intravenous injection education method for the nursing student by identifying the relations between the knowledge of the intravenous injection, self-confidence, and competence of the nursing student.

\section{Methods}

\subsection{Study design}

This study is a descriptive study performed to verify the degree of knowledge on the intravenous injection, self-confidence, competence, and critical thinking disposition in the nursing student and to find out the relations among them.

\subsection{Research subject}

The subjects of this study were 158 students who as nursing students of a university located in K Province, have heard the explanation of the purpose and process of the research in advance and agreed voluntarily to participate in the study.

\subsection{Measurements}

\subsubsection{Knowledge of intravenous injection}

To measure the knowledge on intravenous injection, the researchers developed a total of 20 questions based on the Evidence-based Practice Guidelines-Intravenous Injection Therapy by Hospital Nurses Association and their content validity was verified through the consultation of 2 professors in basic nursing and 3 clinical experts. The right answer for each question was processed with 1 point and the wrong answer was with 0 points, and the range of the score was 0 to 20 points, and the higher the score, the higher the knowledge. The reliability of this study was KR (Kuder-Richardson) $-20=.91$.

\subsubsection{Self-confidence on intravenous injection}

The self-confidence on the intravenous injection was measured using the questionnaire to measure the self-confidence on the intravenous injection designed by Eugun, et. al [9] The measurement tool of self-confidence on the intravenous injection was 5 questions and measured with a 5-point Likert scale, and the high the score, the higher the self-confidence. Cronbach's alpha at the time of developing the instrument was .88 and in this study, it was .92 . 


\subsubsection{Intravenous injection competence}

To measure intravenous injection competence, out of the Core Fundamental Nursing Skills of the Accreditation Board of Nursing Education [10] 29 questions in the intravenous injection checklist were used evaluating the non-performance as 0 points and performance as 1 point based on the theoretical evidence of the Basic Nursing Practice Textbook[11]. In this study, KR (Kuder-Richardson) -20 was .90.

\subsubsection{Critical thinking disposition}

For the critical thinking disposition, the measuring instrument of critical thinking disposition developed by Yoon [8] was used. This tool has a total of 27 questions composed of 7 sub-categories of sound skepticism, intellectual fairness, objectivity, system, prudence, intellectual passion/curiosity, and self-confidence. Each question was measured with a 5-point Likert scale from 1 point (Not at all) to 5 points (Absolutely right). The higher the score, the higher the critical thinking disposition, and for the reliability of the instrument, Cronbach's alpha in the research by Yoon [8] was .89 and in this study, it was .95 .

\subsection{Data collection}

The data has been collected from November 28, 2016, to December 16, the intravenous injection skill practice period after the theoretical class on intravenous injection.

\subsection{Data analysis}

The collected data was analyzed using SPSS 20.0. For the general characteristics of the subject, descriptive statistics were performed and the difference in the dependent variables according to the general characteristics was analyzed with t-test, one-way ANOVA. For the post hoc analysis, the scheme test was used. In addition, to find out the relations among the knowledge, self-confidence, competence of the intravenous injection, and critical thinking disposition, Pearson's correlation analysis was performed.

\subsection{Ethical considerations}

This researcher explained the purpose of this study and that the collected data is encoded anonymously by computer and will not be used other than the research purpose. And after explaining that participating in the study is voluntary and the data collection started.

\section{Results}

\subsection{General characteristics of the subject}

The subjects who participated in this study were mostly female (87.7\%). In the grade of the previous semester, 3.5 to 4.0 was 57 (37.0\%), and 3.0 to 3.5 was $48(31.2 \%)$. Of the students who satisfied with the basic nursing practice was 110 (71.4\%) occupied the majority. And no student does not have an interest in the practice. In addition, those who showed an active attitude toward the practice were $95(61.7 \%)$. 


\subsection{Subject's knowledge, self-confidence, competence of intravenous injection, and critical thinking disposition}

The subject's average score of knowledge on the intravenous injection was 10.16 points and the average score of self-confidence on it was 23.56 points. The average score of the subject's intravenous injection competence was 26.56 points and the average score of the subject's critical thinking disposition was 101.62 points.

\subsection{Difference in subject's knowledge, self-confidence, competence of intravenous injection, and critical thinking disposition}

The self-confidence of the intravenous injection was shown a significant difference in satisfaction with practice $(\mathrm{F}=9.78, p<.001)$, interest in practice $(\mathrm{t}=17.43, p<.001)$, attitude toward the practice $(\mathrm{F}=10.66, p<.001)$. The critical thinking disposition showed he significant difference in satisfaction with practice $(\mathrm{F}=6.43, p=.002)$, interest in practice $(\mathrm{t}=14.77$, $p<.001)$, and attitude toward the practice $(\mathrm{F}=8.83, p<.001)$.

\subsection{Relations among knowledge, self-confidence, the competence of intravenous injection, and critical thinking disposition}

The self-confidence in intravenous injection showed a strong positive correlation with competence $(\mathrm{r}=.70, p<.001)$. In addition, the relationship between critical thinking disposition and self-confidence showed a weak positive correlation $(\mathrm{r}=.17, p<.05)$.

\section{Discussion}

This study was performed to identify the degree of knowledge, self-confidence, competence of the intravenous injection, and the critical thinking disposition in the nursing student, and the relation among them.

First, in this study, self-confidence in intravenous injection was significant with satisfaction with the practice, interest in the practice, and attitude toward the practice, which is similar to the prior research results performed with the nursing students showing that there is a correlation between the self-confidence and the satisfaction with the practice when performing the clinical practice [7].

Since as invasive nursing, the intravenous injection has a higher risk of failure and is likely to occur patient safety problems, the intravenous injection skills are educated mostly utilizing the practice model. This would drop the self-confidence for the intravenous injection and reduce the interest related to intravenous injection skills. Therefore, to maintain the interest continuously in the intravenous injection among the nursing student and to enhance satisfaction with practice through a positive attitude, the changing curriculum.

The self-confidence of the intravenous injection showed a strong positive correlation with competence. Since there is no prior research on the relationship between self-confidence and competence performed by nursing students, the comparative analysis is difficult. But the prior research [12] that showed the significant difference in the success of intravenous injection according to self-confidence after educating the simulation-based intravenous injection, would support the results of this study indirectly. In addition, after learning the knowledge, and skill of the intravenous injection and applying the program to the nursing student, the knowledge, self-confidence, and comfort related to the intravenous injection were increased[2][6]. 
Also, the critical thinking disposition showed significant satisfaction with the practice, interest in the practice, and attitude toward the practice, which is similar to the research by Yoon [12] showing that the critical thinking disposition on patient safety has significant relations with the satisfaction and attitude toward the practice. And the self-confidence for the intravenous injection showed to have a significant correlation with the critical thinking disposition. Since there is no research on the relationship between self-confidence for basic nursing skills and critical thinking disposition, a comparative analysis is difficult. But according to prior research [13], self-confidence in ethical decision-making can enhance the critical thinking disposition, As a student can find and solve problems by themselves through intravenous injection skills and judge more prudently, not only their critical thinking disposition is enhanced and their self-confidence could be enhanced.

Through the above results, the knowledge and the clinical application should be integrated matching the step with the expectation of patients and the medical environment being changed, and to produce the nurses with ability, integrating the knowledge and the technique through the practice education considering the safety of the patient and developing the critical thinking disposition in the nursing student are essential.

\section{Conclusion}

This study attempted to identify the correlation among the knowledge, self-confidence, competence of the intravenous injection skill, and the critical thinking disposition in the nursing student. In the results of the study, the self-confidence for the intravenous injection and the critical thinking disposition in the subject having high satisfaction with the practice and interest in the practice were shown high and the positive correlation among the selfconfidence, the competence of intravenous injection, and the critical thinking disposition was shown. This study has limitations to generalize its results as the results subjects were limited to nursing students in one university. The research to verify the knowledge, self-confidence, competence of the intravenous injection, the critical thinking disposition, and the degree of change in the nursing student is required.

\section{Acknowledgments}

The authors thank the nursing students who participated in this study.

\section{References}

[1] S. S. Dychter, D. A. Gold, D. Carson, and M. Haller, "Intravenous therapy: A review of complications and economic considerations of peripheral access," J. Infusion Nursing, vol.35, no.2, pp.84-91, (2012) DOI: 10.1097/NAN.0b013e31824237ce

[2] N. L. Keleekai, C. A. Schuster, C. L. Murray, M. A. King, B. R. Stahl. L. J. Labrozzi, S. Gallucci, M. W. LeClair, and K. R. Glover, "Improving nurses' peripheral intravenous catheter insertion knowledge, confidence, and skills using a simulation-based blended learning program: A randomized trial," Simulation in Healthcare, vol.11, no.6, (2016) DOI: 10.1097/SIH.0000000000000186

[3] R. E. Helm, J. D. Klausner, J. D. Klemperer, L. M. Flint, and E. Huang, "Accepted but unacceptable: Peripheral IV catheter failure," J. Infusion Nursing, vol.38, no.3, pp.189-203, (2015) DOI: 10.1097/NAN.0000000000000100 
[4] M. K. Jeon and H. J. Jung, "Nursing students who have experienced by clinical practice recognition type of core fundamental nursing skills," J. the Korea Convergence Society, vol.9, no.3, (2018) DOI: 10.15207/JKCS.2018.9.3.297

[5] J. A. Park and J. Y. Hong, "Effect of self-directed learning ability, ego resilience, critical thinking disposition on the competency of nursing students basic nursing skills," J. The Korea Contents Association, vol.16, no.1, pp.342-351, (2016) DOI: 10.5392/JKCA.2016.16.01.342

[6] R. Jensen, "Teaching students about intravenous therapy: Increased competence and confidence," J. the Association for Vascular Access, vol.14, no.1, pp.21-26, (2009) DOI: 10.2309/java.14-1-4

[7] J. S. Park, M. J. Choi, and S. Y. Jang, "The effects of preclinical clinical performance examination on nursing students' confidence in nursing skills and critical thinking competence," J. Korean Academic Society of Nursing Education, vol.21, no.1, pp.75-85, (2015) DOI: 10.5977/jkasne.2015.21.1.75

[8] J. Yoon, "Development of an instrument for the measurement of critical thinking disposition: In nursing, Doctoral dissertation," The Catholic University, Seoul, (2004)

[9] S. A. Engum, P. Jeffries, and L. Fisher, "Intravenous catheter training system: Computer-based education versus traditional learning methods," The American J. Surgery, vol.186, no.1, pp.67-74, (2003) DOI: 10.1016/S0002-9610(03)00109-0

[10] Korean Accreditation Board of Nursing Education, Retrieved September 15, 2017, from the web site: http://www.kabone.or.kr, (2017)

[11] K. A. Song, "Fundamentals of nursing interventions \& skill," Soomoonsa: Seoul, (2017)

[12] J. W. Yoon, "Relationships among attitude of patient safety, critical thinking disposition and safety nursing activities in nursing students," J. Learner-Centered Curriculum and Instruction, vol.17, no.23, (2017)

[13] M. H. Lim, "Effects of moral sensitivity and critical thinking disposition on perceived ethical confidence in nursing students," J. the Korea Academia-Industrial cooperation Society, vol.17, no.9, pp.610-618, (2016) DOI: 10.5762/KAIS.2016.17.9.610 